\title{
A dialogicidade enquanto prática educativa na formação de discentes
}

\author{
Dialogicity as educational practice in the formation of discent \\ Dialogicidad como práctica educativa en la formación de discentes
}

Recebido: 08/10/2020 | Revisado: 11/10/2020 | Aceito: 11/01/2021 | Publicado: 19/02/2021

\author{
Jamila Hunára da Silva Santos \\ ORCID: https://orcid.org/0000-0002-9564-0267 \\ Universidade Estadual do Ceará, Brasil \\ E-mail: jamilahunara@gmail.com \\ Ana Cristina de Moraes \\ ORCID: https://orcid.org/0000-0002-8650-8272 \\ Universidade Estadual do Ceará, Brasil \\ E-mail: cris.moraes@uece.br \\ Georgia Tath Lima de Oliveira \\ ORCID: https://orcid.org/0000-0001-5492-1671 \\ Universidade Estadual do Ceará, Brasil \\ E-mail: georgia.tath@aluno.uece.br
}

\begin{abstract}
Resumo
Neste artigo, discutimos sobre as possibilidades da dialogicidade como elemento epistemológico, político e pedagógico de forma a pensar o desenvolvimento do senso crítico e humano. Entendemos que, ao propiciar momentos reflexivos, o docente pode ampliar as perspectivas de ensino e de aprendizagem, permitindo que o sujeito se aproprie de ferramentas para desvelar possibilidades de atuação no mundo. Desse modo, partimos aqui da seguinte questão norteadora: Qual é o lugar da dialogicidade enquanto elemento epistemológico, político e pedagógico no ensino e na aprendizagem de discentes? E das seguintes questões secundárias: de que modo podemos pensá-la como prática educativa para o desenvolvimento do senso crítico e o aperfeiçoamento humano? Como os discentes pensam a dialogicidade na aprendizagem? Este trabalho é fruto das reflexões advindas de uma atividade proposta por nós com a temática Psicologando: a cultura e suas interfaces a partir da fotografia, realizada nos cursos de Psicologia, Recursos Humanos, Marketing e Análise de Desenvolvimento de Sistemas. Ressaltamos que este estudo enfoca a vivência que essa atividade proporcionou aos alunos, trazendo as percepções dos discentes do primeiro semestre do curso de Psicologia, em uma instituição de Ensino Superior privada localizada no município de Maracanaú-CE, durante o semestre 2019.2. Entendemos que essa atividade permitiu refletir sobre o processo de ensino e aprendizagem, de modo a perceber sua importância e perspectivas, a partir da práxis e do olhar dos alunos, problematizando a dialogicidade na prática educativa e suas contribuições para a formação dos discentes.
\end{abstract}

Palavras-chave: Ensino-aprendizagem; Prática educativa; Dialogicidade; Formação docente.

\begin{abstract}
In this study, we discuss the possibilities of dialogicity as an epistemological political pedagogical element in order to think about the development of both critical and human senses. We understand that, by providing reflective moments, the teacher can broaden the perspectives of teaching and learning, making it possible for the subject to take hold of tools to reveal possibilities of acting in the world. Thus, we start from the following guiding question: What is the role of dialogicity as an epistemological political pedagogical element in teaching and in students' learning? Also, from the secondary questions: How can we think of it as an educational practice for the development of critical sense and for human improvement? And how do students think of dialogicity in learning? This paper is the result of reflections arising from an activity we proposed with the topic Psychologizing: culture and its interfaces from photography, carried out in the following courses: Psychology, Human Resources, Marketing and Systems Development Analysis. We highlight that this study focuses on the experience that this activity provided to students, bringing the perceptions of the ones in the first semester of the Psychology course, in a private Higher Education institution located in Maracanaú town, in the state of Ceará, throughout the semester 2019.2. We understand that this activity allowed us to reflect on the teachinglearning process in order to realize its importance and perspectives, from the students' praxis and view, problematizing the dialogicity in educational practice and its contributions to the education of students.
\end{abstract}

Keywords: Teaching-learning; Educational practice; Dialogicity; Teacher education.

\section{Resumen}

En este artículo, discutimos sobre las posibilidades de la dialogicidad como elemento epistemológico, político y pedagógico de modo a pensar en el desarrollo del sentido crítico humano. Comprendemos que, al propiciar momentos reflexivos, el docente puede ampliar las perspectivas de enseñanza y aprendizaje, haciendo con que el sujeto se apropie 
de las herramientas para desvelar posibilidades de actuación en el mundo. De ese modo, partimos de la siguiente cuestión rectora: ¿Cuál el sitio de la dialogicidad como elemento epistemológico, político y pedagógico en la enseñanza y el aprendizaje de discentes? Y de las siguientes cuestiones secundarias: ¿Cómo podemos pensarla mientras práctica educativa para desarrollo del sentido crítico y perfeccionamiento humano? ¿Cómo los discentes piensan la dialogicidad en el aprendizaje? Este trabajo es fruto de las reflexiones advenidas de una actividad que propusimos nosotras con la temática Psicologando: la cultura y sus interfaces a partir de la fotografía, para los cursos de Psicología, Recursos Humanos, Marketing y Análisis de Desarrollo de Sistemas. Destacamos que este estudio se vuelca hacia la vivencia que la actividad proporcionó a los alumnos, trayendo las percepciones de los discentes del primer semestre del curso de Psicología, en una institución de Enseñanza Superior privada, ubicada en la ciudad de Maracanaú-CE, durante el semestre 2019.2. Comprendemos que esa actividad permitió reflexionar acerca del proceso de enseñanza y aprendizaje, permitiendo percibir su importancia y perspectivas, a partir de la praxis y de la mirada de los alumnos, problematizando la dialogicidad en la práctica educativa y sus contribuciones para la formación de los discentes.

Palabras clave: Enseñanza-aprendizaje; Práctica educativa; Dialogicidad; Formación docente.

\section{Introdução}

Acreditamos que todo processo de aprendizagem passa pela dor e alegria de conhecer o mundo e a forma como ele se apresenta. Somos, em boa medida, milhares de curiosos aventurando-nos na infinidade que o ato de aprender nos possibilita vivenciar. A dor de aprender a aprender, aprender a ensinar e aprender a desaprender faz com que tenhamos que traçar muitos caminhos para chegar a lugares que, na maioria das vezes, são desconhecidos. A dor de ter que voltar alguns passos e entender que é normal e até necessário, a dor de ver e rever, depois fazer, refazer e dançar essa ciranda repetidas vezes, mas nunca de forma estática, vai nos direcionando, não rumo à perfeição, mas ao aperfeiçoamento.

É por isso que também acreditamos que aprender e ensinar são constantes processos de pinturas e raspagens ${ }^{1}$ que vamos tendo contato ao longo da vida, são infinitas cores, borrões, tentativas e possibilidades de fazer um quadro memorável e emocionante. O que diferencia uma obra de arte da outra é a intenção, a perspectiva e a motivação por trás do resultado final.

Neste estudo, objetivamos discutir as possibilidades da dialogicidade enquanto elemento epistemológico, político e pedagógico para o ensino e a aprendizagem dos discentes, a fim de pensar o desenvolvimento do senso crítico e humano dos envolvidos. E refletir sobre a importância da compreensão dos discentes a respeito da dialogicidade e do processo de ensino e aprendizagem para as suas formações. Entendemos que, ao propiciar momentos reflexivos, o professor pode ampliar as perspectivas de ensino e de aprendizagem, proporcionando ao sujeito possibilidades de desenvolver condições propícias para sua atuação no mundo. Nessa direção, Freire (2006) enfatiza que o ensino, a aprendizagem e o desenvolvimento humano são fenômenos eminentemente sociais, permeados pela afetividade, bem como por referências éticas, políticas e estéticas.

Desse modo, neste artigo partimos do seguinte problema norteador: Qual é o lugar da dialogicidade enquanto elemento epistemológico, político e pedagógico no ensino e na aprendizagem de discentes? Além deste, levantamos as seguintes questões secundárias: de que modo podemos pensá-la como prática educativa para o desenvolvimento do senso crítico e o aperfeiçoamento humano? Como os discentes pensam a dialogicidade na aprendizagem?

\section{Metodologia}

Este trabalho é fruto das reflexões advindas de uma intervenção didática, feira cultural, realizada na disciplina de Sociologia, que propomos a partir da temática Psicologando: a cultura e suas interfaces a partir da fotografia, desenvolvida junto aos cursos de Psicologia, Recursos Humanos, Marketing e Análise de Desenvolvimento de Sistemas. Portanto, trata-se de uma pesquisa aplicada, na qual se teve a finalidade de produzir conhecimentos e aplicá-los em um contexto prático para a resolução de problemas específicos. É um estudo descritivo e exploratório, onde o primeiro teve como objetivo descrever e

\footnotetext{
${ }^{1}$ Parafraseando Rubem Alves, que diz: "Eu quero desaprender para aprender de novo. Raspar as tintas com que me pintaram. Desencaixotar emoções, recuperar sentidos" (Alves, 2011).
} 
interpretar a realidade, sem inferir relações de causalidade. Já o segundo buscou levantar informações sobre determinado objeto, delimitando dessa forma um campo de trabalho e mapeando as condições manifestadas pelo mesmo (Severino, 2007).

Além disso, possui natureza qualitativa. Para Minayo (2001), essa abordagem refere-se ao levantamento das informações, a partir da natureza da história, das relações, das representações das crenças e das opiniões, produto interpretativo do sujeito, do modo como vivem, constroem sua subjetividade e a si mesmos.

Importante enfatizar que neste artigo discorremos sobre a vivência que o referido momento proporcionou aos alunos, com foco no lugar da dialogicidade inserida nos seus processos de ensino e aprendizagem, trazendo as percepções dos discentes do primeiro semestre do curso de Psicologia de uma instituição de Ensino Superior privada localizada no município de Maracanaú-CE, durante o semestre 2019.2.

Os participantes da pesquisa foram doze alunos de graduação e, para a viabilização do trabalho e da discussão, organizamos os discentes em sete duplas, para as quais foram sorteadas seis perguntas, ficando cada dupla responsável por discutir e responder a uma dessas perguntas. Posteriormente, suas respostas foram apresentadas e discutidas com o grupo maior, tendo sido designado um representante de cada equipe para elaborar um texto sobre os principais pontos discutidos pela dupla.

A proposta do projeto didático foi culminar com a realização de uma exposição fotográfica a partir de temáticas relacionadas à cultura ${ }^{2}$, de modo que esse primeiro momento seguiu a seguinte ordem: divisão das equipes e escolha dos temas; escolha das fotografias relacionadas aos temas - sendo importante mencionar que os discentes ficaram livres para escolher as imagens, podendo ser da internet ou fotos feitas por eles; exposição e apresentação das produções; e feedback das apresentações.

Após essa intervenção, realizamos uma discussão baseada nessa vivência com o intuito de buscar descobrir o que os alunos pensavam sobre a dialogicidade, as aulas, o ensino e a aprendizagem, de modo que pudéssemos dialogar e refletir sobre essas questões a partir de suas falas. Para isso, seguimos as etapas a seguir: discussão em grupo (Flick, 2009) a respeito da vivência; análise das respostas; e devolutiva social. Novamente, frisamos que este artigo não se detém prioritariamente à atividade de exposição fotográfica, mas à discussão feita após esse momento com ênfase no lugar da dialogicidade no processo de ensino e aprendizagem. A ordem mencionada anteriormente serve apenas para que se tenha noção de que a discussão foi um recorte de um momento ainda mais amplo.

Assim, este estudo foi pensado e organizado com base em um referencial teórico com o qual discutimos conceitos que consideramos principais, como: ensino; aprendizagem; formação; práxis; prática educativa; e dialogicidade, bem como na análise de dados, na qual discutimos criticamente os conteúdos das respostas a partir das contribuições de Faria (2018), Rios, Ghelli e Silveira (2016), Almeida (2015), Barroso (2015), Almeida (2012), Bulgraen (2010), Saviani (2008), Cerqueira e Kelly (2006), Freire (2006), Ribeiro e Soares (2006), Anastasiou e Alves (2005), Zabalza (2004), Malusá (2003), Fontana (2000), Libâneo e Pimenta (1999), Zabala (1998) e Libâneo (1994a; 1994b; 1994c). Há ainda as considerações finais, nas quais fazemos uma síntese dos achados da pesquisa, assim como das aprendizagens decorrentes da atividade que buscou integrar aspectos teóricos e práticos.

\footnotetext{
${ }^{2}$ Foram sorteados os seguintes temas: Cultura; Multiculturalismo; A construção de grupos; Identidade; Cultura cearense; e Tradição e modernidade. Posteriormente, solicitamos que, a partir desses assuntos, cada membro das equipes selecionasse uma fotografia que tivesse relação com o tema. Após essa escolha, solicitamos também que montassem uma apresentação - fundamentando-se - tendo em vista essa relação, com foco nas mensagens e significados que as fotos representavam ou poderiam representar.
} 


\section{Resultados e Discussão}

As ideias aqui manifestadas respaldam-se na análise das respostas da entrevista coletiva como elemento problematizador da compreensão dos sujeitos sobre a questão norteadora: Qual é o lugar da dialogicidade, enquanto elemento epistemológico, político e pedagógico no ensino e na aprendizagem de discentes?

As práticas e desafios envolvidos no processo de ensinar estão cada vez mais voltados às necessidades dos alunos, considerando a realidade na qual estão inseridos, a fim de propor intervenções e reflexões. A ação do professor precisa estar pautada em objetivos pedagógicos, uma vez que trabalha com pessoas em busca de desenvolvimento profissional. Dessa forma, trabalhar com eles somente na perspectiva teórica não representa a realidade e muito menos a proposta de agir sobre o mundo (Almeida, 2015). Nesse sentido, quando questionados sobre essa pergunta, os alunos que mencionamos anteriormente responderam:

Bem, uma aula dialógica é aquela que dá pra gente interagir, que a gente entenda o que está sendo falado e que converse com a nossa realidade. Percebemos que tem muitos professores parados, que não explicam bem o conteúdo e que às vezes parecem perdidos na sala de aula. Isso é desmotivador, muito ruim, porque a gente já tem tanta coisa na cabeça, vem de um dia corrido e cansativo que ao nos depararmos com esse tipo de aula não conseguimos aprender. Em contrapartida, tem aulas muito boas que nos instigam a aprender, temos espaço para falar, discordar e concordar com as ideias colocadas pelos autores que estudamos e pela própria professora. Gostamos muito da forma como é conduzida a aula, a gente ri, conversa e se sente à vontade para participar, e isso acontece sem a utilização de muitas ferramentas, apenas a fala e os textos mesmo e isso é muito bom. Achamos que isso é ter uma aula dialógica e construtiva. Quando temos esse tipo de aula fazemos de tudo para não faltar, para ler os textos, para participar das discussões e nos sentimos motivados, se torna um cansaço suportável e até divertido, por isso a gente considera esta aula sendo um modelo a ser seguido (Dupla 1).

Percebemos, então, ser fundamental que, mais do que o uso de ferramentas no ambiente educacional, os professores universitários adotem uma postura de compreensão em sala, estimulando a participação, a troca de conhecimentos, e possibilitando o desenvolvimento da autonomia e senso crítico nos alunos. Desse modo, a qualidade das aulas e do conteúdo apontado pelos participantes não está relacionada a recursos didáticos utilizados por alguns professores, mas à forma como os mesmos conseguem conduzi-los.

Para Almeida (2015), o fazer didático deve ser aplicado, pois é através dele que ocorrerá a reflexão nos momentos de aprendizagem, partindo inicialmente da realidade na qual estão inseridos professores e alunos, direcionando-se, em seguida, a vários outros contextos de vivências e habilidades. Nessa lógica, os desafios e práticas docentes devem ser encarados como sendo uma oportunidade de (re)pensar o ensino e a aprendizagem e seus impactos na relação professor-aluno.

Para Libâneo (1994a), aprender diz respeito ao processo de assimilação de qualquer conhecimento, desde os mais simples até aqueles mais complexos. Além disso, a todo momento a pessoa está aprendendo e adquirindo novos conhecimentos, seja por meio da educação formal ou por meio das experiências do dia a dia. Desse modo, para que a aprendizagem ocorra é preciso que haja todo um processo de assimilação, o qual, em contexto escolar, necessita da orientação do professor para que o aluno possa compreender, refletir e aplicar os conhecimentos adquiridos.

Ainda sobre esse processo, as pessoas selecionam os conteúdos com base em seus interesses e na relação que estabelecem com o que está sendo aprendido. Nesse sentido, a aprendizagem é compreendida como sendo uma prática que ultrapassa os limites da mera observação, colocando a pessoa de forma ativa no processo. $\mathrm{O}$ autor acima referido, entende que o professor na sala de aula atua como um mediador entre o conhecimento e o aprendente e, por fazer parte desse processo, também aprende e não somente ensina. Por isso, ele pontua que esse processo precisa ter a motivação como seu alicerce para continuar a existir, pois 
A motivação é intrínseca quando se trata de objetivos internos, como a satisfação de necessidades orgânicas ou sociais, a curiosidade, a aspiração pelo conhecimento; é extrínseca, quando a ação da criança é estimulada de fora, como as exigências da escola, a expectativa de benefícios sociais que o estudo pode trazer, a estimulação da família, do professor ou dos demais colegas (Libâneo, 1994a, p. 88).

Desse modo, para que a aprendizagem se efetive, torna-se necessário que o professor pense, organize e realize atividades de forma que atendam às necessidades dos alunos, considerando-os ativos no processo e possibilitando que descubram e indiquem alternativas de aprendizagem. Ressalta ainda que a aprendizagem é algo que não apenas ocorre e se estagna, mas é capaz de modificar o pensamento e movimentar o sujeito, a ação e a mudança e, para isso, é preciso que haja estímulo para aprender os conteúdos abordados, textos e discussões que condizem com a realidade social dos que estudam.

Quando questionados sobre de que forma os professores poderiam ensinar de modo a fazer com que o conteúdo e a aula se tornassem mais dialógicos, percebemos um discurso muito relacionado às ideias de Barroso (2015), nas quais afirma que a aula deve ser um espaço onde os alunos se sintam estimulados, desafiados, esfomeados e, ao mesmo tempo, confortáveis e familiarizados com o ambiente. Do contrário, mal elaborada e desagradável, faz com que os alunos percam o interesse, mesmo que inicialmente estejam querendo aprender, vindo a não prosseguir devido à falta de afinidade com a proposta.

Percebemos esse discurso na seguinte fala:

Achamos que depende muito da disciplina, mas de forma geral, os professores poderiam ser mais dinâmicos, didáticos e ensinar exemplificando. Tem muito assunto que é interessante, mas não é abordado dessa forma e acaba se tornando chato. O professor não precisa, necessariamente, de muitos equipamentos e/ou dinâmicas, mas precisa ser mais dialógico. Tem alguns professores que querem fazer dinâmica com a gente quase que em todas as aulas e dar o conteúdo que é bom, nada, e já tem professores que só falam e falam, nem abertura dão para que possamos nos expressar. Essas duas realidades são maçantes. Mas percebemos que tem docentes que conseguem usar o meio termo como essa aula, que tanto propõe momentos criativos e reflexivos quanto consegue ensinar apenas usando o texto, sem diminuir a nossa empolgação. Então, uma sugestão seria tentar partir da nossa realidade, ter contato com a turma e conversar com a gente (Dupla 2).

Diante disso, o docente torna-se responsável por buscar estratégias adequadas para capturar a atenção do estudante, estimulando a aprendizagem e o desejo contínuos nesse processo. As estratégias utilizadas irão variar em cada caso, mas o fundamental é que sejam realizados momentos significativos para os alunos, não sendo necessário, para isso, lançar mão de equipamentos supérfluos em todas as aulas, muito menos que seja utilizado apenas o texto sem que ocorra o diálogo e a reflexão sobre o mesmo (Barroso, 2015).

No âmbito da formação docente, a premissa freireana, de que é cada vez mais possível se perceber a relevância que a dialogicidade tem para potencializar a constituição e a apreensão de saberes, mostra-se muito atual e contundente.

Segundo Zabalza (2004, p. 93), “formar é preparar para o exercício de práticas direcionadas e contextualizadas nas quais o saber só adquire sentido com referência ao objetivo perseguido". Desse modo, a formação se diferencia do ensino, mas implica a aquisição de saberes. Logo, as instituições de ensino precisam perceber as práticas pedagógicas como sendo responsáveis também por desencadear resultados sólidos e capazes de estabelecer relações saudáveis na promoção do conhecimento.

Muitos profissionais defendem a ideia de que para ensinar no ambiente universitário é necessário apenas o domínio dos conhecimentos específicos da área, fazendo com que muitas instituições tenham recebido profissionais de diversas áreas do conhecimento, mas que, em sua maioria, apesar de possuírem experiências e estudos nas áreas específicas, não possuem preparo e conhecimento dos processos de ensino e aprendizagem (Rios, Ghelli \& Silveira, 2016).

A terceira pergunta traz reflexões a respeito das habilidades dos professores: É necessário que o professor tenha alguma habilidade para obter uma boa relação com os alunos? Segundo Freire (2006), o educador não tem a função de apenas educar, 
mas também de participar dessa troca e aprender juntamente. Assim, no diálogo com o educando, deve haver uma postura aberta e comedida.

Nesse sentido, pode-se afirmar que o professor deve adotar uma atitude democrática, de respeito e de flexibilidade em relação ao aluno, sendo capaz de mediar e ampliar o conhecimento de modo a somar com o que o educando já adquiriu. É relevante destacar que aqui o professor ocupa um lugar de mediador capaz de constituir um caminho para ampliar os significados e até mesmo de ressignificar seus pontos de vista e ideias (Freire, 2006). Por isso que, quando questionados, os alunos trouxeram a seguinte resposta:

Sim, um professor precisa saber lidar com a turma, saber transmitir o conteúdo e conseguir prender a nossa atenção, fazer com que queiramos aprender ainda mais. Além disso, a gente acredita que ele precisa ter uma boa relação com os alunos, ser paciente com as limitações e dinâmicas das turmas, sem que seja agressivo e/ou nos repreenda. Gostamos quando um docente parece gostar do que faz e se importar tanto com a nossa evolução quanto com os nossos limites, é fundamental nos sentirmos parte de um todo e não apenas qualquer um. Ao conversar sobre esse assunto no grupo é unânime quando afirmamos que é preciso que o professor saiba mais do que o conteúdo, mas que consiga dar sentido ao que estudamos, pois temos professores que são muito inteligentes e a gente percebe que sabem, mas não conseguem nos ensinar e acabamos sendo prejudicados (Dupla 3).

Segundo Almeida (2015), o professor que adere a atitudes imperativas, sem diálogos e sem escutar o que os alunos têm a dizer, contribui para a perda do interesse na aprendizagem. Esse tipo de imposição e postura priva os alunos de um ambiente reflexivo e dinâmico. E é exatamente isso que os entrevistados pontuam em sua fala, demonstrando que também se preocupam em estar inseridos em um espaço de equilíbrio e de troca, demonstrando a necessidade de desenvolver sua autonomia. Além disso é importante mencionar que os professores precisam ser cautelosos para não se tornarem profeshows ${ }^{3}$, mais preocupados com o espetáculo e a performance do que com o ensino reflexivo e de qualidade.

De acordo com Zabala (1998), a prática educativa tem como estrutura os seguintes elementos: a concepção de ensino e aprendizagem; a função dos professores e alunos; a organização do espaço e do tempo; a organização dos conteúdos; a escolha e uso dos materiais e recursos didáticos; o sentimento; e a avaliação realizada institucionalmente pelo professor e pelos alunos. Cerqueira e Kelly (2006), por sua vez, assinalam que a prática educativa é conceituada como sendo um conjunto de ações realizadas pelos professores em um contexto educacional e os objetos são tanto socialmente determinados, através das condições adequadas e possíveis, quanto utilizados a partir da experiência, filosofia e objetivo do docente.

$\mathrm{Na}$ perspectiva de um processo de ensino-aprendizagem permeado pela dialogicidade, Freire (2006, p. 135-136) nos inspira ao anunciar a necessidade da abertura ao encontro, ao respeito e ao diálogo com o outro, afirmando que

Testemunhar a abertura aos outros, a disponibilidade curiosa à vida, a seus desafios, são saberes necessários à prática educativa. Viver a abertura respeitosa aos outros e, de quando em vez, de acordo com o momento, tomar a própria prática de abertura ao outro como objeto da reflexão crítica deveria fazer parte da aventura docente. A razão ética da abertura, seu fundamento político, sua referência pedagógica; a boniteza que há nela como viabilidade do diálogo. A experiência da abertura como experiência fundante do ser inacabado que terminou por se saber inacabado.

A quarta pergunta lançada foi: Como se sentem em relação às atividades propostas pelos professores? Na Educação Básica, costuma-se exigir dos professores uma postura dialógica e de mediação em sala de aula que estimule a participação dos alunos com propostas de atividades criativas que possam envolvê-los no processo de aprendizagem, apresentando-lhes outras perspectivas e despertando-lhes o interesse pelos conteúdos e por colocá-los em prática (Almeida, 2015).

\footnotetext{
${ }^{3}$ Expressão utilizada pela autora.
} 
Contudo, nas etapas seguintes de formação, principalmente no Ensino Superior, a realidade é diferente. A mediação dos assuntos discutidos em sala torna-se sobrecarregada, havendo mais cobrança pela aprendizagem de conteúdos específicos, com tempo reduzido e um volume maior de conhecimentos a serem aprendidos. O problema pontuado é que se o aluno não estiver engajado e/ou não estiver habituado a esse tipo de cobrança, termina por abandonar sua formação ou a permanecer e terminá-la de qualquer jeito (Almeida, 2015).

Percebe-se essa afirmação na seguinte declaração:

Sufocados, às vezes. Temos quatro tipos de avaliações e elas ocorrem pelas disciplinas na mesma semana e isso tem nos deixado muito cansados e desmotivados. São poucas as disciplinas que conseguimos relaxar e acompanhar as discussões. Elas são ruins porque não conseguimos aproveitar os momentos, pois ficamos sobrecarregados com tanta coisa, afinal a maioria das pessoas do grupo são mães e pais, trabalham e tem uma casa para cuidar. Outra coisa negativa é que as avaliações são repetitivas, sem muita criatividade. Achamos que é por isso que gostamos tanto dessa atividade da exposição e da maioria das ideias trazidas por essa disciplina, porque foge dos padrões e temos liberdade para propor também, na semana do trabalho foi muito corrida, mas foi a melhor que tivemos, superou as nossas expectativas (Dupla 4).

Percebemos que há uma enorme diferença entre a Educação Básica e o Ensino Superior relacionada à didática, dificultando o desempenho dos alunos que não tiveram uma educação de qualidade, com acesso restrito a conteúdos e abordagens de ensino. Principalmente porque ainda existe uma tendência, por parte de alguns professores, em manter uma postura tradicional de ensino, disseminando, muitas vezes, a ideia de que ao se fazer uso de metodologias ativas e outros recursos estão desenvolvendo uma didática adequada, quando na verdade o processo é muito mais complexo (Almeida, 2015).

Os alunos se queixam das inúmeras atividades que precisam realizar, da falta de diálogo e de alternativas nas propostas e da pouca oportunidade de participação nas escolhas dos trabalhos, questionando seu sentido e, inclusive, a sua eficácia na aprendizagem. O cansaço, os diversos papeis e responsabilidades que possuem são trazidos como aspectos que dificultam ainda mais na aprendizagem, além de serem elementos que precisam ser levados em consideração pelos docentes.

Já o conceito de ensino significa uma atividade que objetiva a aprendizagem do outro; para que isso ocorra é preciso que o educador, enquanto mediador do conhecimento, se utilize de métodos e técnicas adequadas e contextualizadas, ou seja, “a relação entre ensino e aprendizagem não é mecânica, não é uma simples transmissão do professor que ensina para um aluno que aprende" (Libâneo, 1994b, p. 90). Assim, vemos que existe uma diferença nessa prática, uma vez que "é uma relação recíproca na qual se destacam o papel dirigente do professor e a atividade dos alunos [...] o ensino visa estimular, dirigir, incentivar, impulsionar o processo de aprendizagem dos alunos" (Libâneo, 1994b, p. 90).

Logo, ensinar requer uma estrutura que objetiva alcançar a aprendizagem do aluno por meio do conteúdo. Essa relação de ensino e aprendizagem não pode ser estabelecida tendo como base a memorização e os alunos também não podem ser negligenciados. Segundo esse mesmo autor, o “[...] processo de ensino, ao contrário, deve estabelecer exigências e expectativas que os alunos possam cumprir e, com isso, mobilizem suas energias. Tem, pois o papel de impulsionar a aprendizagem e, muitas vezes, a precede" (Libâneo, 1994c, p. 91).

Para que os alunos não adquiram um conhecimento baseado apenas na teoria ou no senso comum, torna-se necessário fazer circular conteúdos de caráter reflexivo, crítico e que tenham uma continuidade, não sendo apenas transmitidos, mas problematizados, discutidos e vivenciados. Desse modo, o foco nos processos de ensino e aprendizagem não deve estar somente no aluno, mas também no professor, compreendendo a necessidade de aprimoramentos e atualizações, sendo essa tarefa de responsabilidade do mesmo e da instituição de ensino (Barroso, 2015).

Outro ponto mencionado diz respeito à relação ensino-aprendizagem, na qual existe a falta de conhecimento, por parte dos alunos, no que tange ao que é exigido em cada disciplina, por isso é importante que o professor exerça um papel de 
transparência em suas ações e objetivos para que os estudantes possam participar do processo de forma a, também, se comprometer a cumprir com os objetivos propostos (Barroso, 2015).

Libâneo (1994b, p. 159) esclarece que "a assimilação de conhecimentos não é conseguida se os alunos não demonstram resultados sólidos e estáveis por um período mais ou menos longo". Assim, o ensino é uma relação na qual o professor põe em prática o tripé objetivo, conteúdo e método, tendo como resultado a aprendizagem do aluno.

É nessa relação que a importância da escolha de métodos e abordagens de ensino são fundamentais, variando do local, nacionalidade, realidade social, dentre outros aspectos. Dessa forma, o professor precisa perceber o ambiente no qual está inserido e propor alternativas de posturas que propiciem o ensino. Ressaltamos que não são as chamadas metodologias ativas que estão sendo consideradas neste trabalho - uma vez que compreendemos que o método faz parte da didática e não é independente -, mas as alternativas que os próprios professores encontram para conseguir agir como mediadores, assim, para algumas turmas, o método expositivo terá maior receptividade, mas, para outras, nem tanto.

Quando questionados sobre: $O$ que vocês entendem por dialogicidade?, percebemos que os alunos, apesar de demonstrarem dificuldade em conceituar e desenvolver uma explicação sobre as temáticas, a compreendem como algo importante e fundamental para que a aprendizagem e o ensino caminhem juntos e não dissociados. Desse modo, uma das respostas foi: "Acreditamos que seja a capacidade do professor e dos alunos de discutirem os conteúdos de forma que todos entendam, por meio de troca de experiências achamos também que os métodos e materiais que eles trazem podem propiciar uma discussão mais interessante" (Dupla 5).

De acordo com Almeida (2015) é fundamental que tanto o aluno quanto o professor repensem suas ações pedagógicas para a construção do conhecimento e para a problematização de hipóteses. Assim, o professor que age como mediador reflexivo vai além dos muros institucionais, vindo a propiciar pesquisa, inovação e transformação, adotando posturas e práticas educativas voltadas ao contexto social. Partindo de sua realidade e fomentando a pesquisa é possível que estimule no aluno sua capacidade crítica e reflexiva em relação aos conteúdos e não apenas à aquisição do conhecimento pelo conhecimento. Além disso, entendemos que o educador não transmite conhecimentos, mas os compartilha em um processo contínuo e construtivo.

Outro ponto a ser mencionado diz respeito ao próprio processo de ensino e aprendizagem. Para Fontana (2000) é preciso que o professor assuma sua função e responsabilidade, tendo objetivos claros sobre a importância do ensinar e do aprender, considerando suas condições intelectuais, sociais, culturais e econômicas. Dessa forma, ao assumir essa responsabilidade, tornase ativo nesse processo e capaz de opinar a partir de seu lugar de fala e de vivência.

O saber envolve um processo muito mais complexo e íntimo do que apenas decorar determinadas fórmulas, frases e lógicas, envolve a afetividade, a curiosidade, o prazer e o desprazer de se construir e reconstruir repetidas vezes no contato com o novo. E isso não é apenas para os discentes, mas também e, principalmente, para os docentes que escolheram ensinar e aprender a partir das suas vivências e conhecimentos, que escolhem servir à educação e mediar aprendizagens, ensinos e sentidos.

Saviani (2008) parte do princípio de que a educação é gerida por produções de saberes, onde o ensino faz parte da ação educativa. Essa perspectiva também deveria estar presente no Ensino Superior, local de produção de conhecimentos, promovendo, assim, o desenvolvimento formativo dos alunos, futuros profissionais. Nas instituições de Ensino Superior, o saber está pautado na ciência, investigando e pesquisando os fenômenos e processos educativos de modo a produzir novos conhecimentos, sem desconsiderar os já existentes (Saviani, 2008).

A sexta pergunta referiu-se à função do aluno nessa relação, ou melhor dizendo: De que modo podemos pensar a dialogicidade como prática educativa para o desenvolvimento do senso crítico e humano?

É exatamente nesse sentido que devem ser pensadas as experiências sociais de cada estudante, de forma a construir, a partir das mesmas, um ambiente acadêmico que lhe propicie segurança para se colocar enquanto personagem de sua própria história e para que perceba suas inseguranças não como algo negativo e paralisador, mas como sendo uma forma de (re)pensar 
seus passos e de abrir-se para novas possibilidades. De acordo com Bulgraen (2010) é nessa perspectiva que devemos considerar as experiências sociais acumuladas, uma vez que o aluno que está em sala de aula traz consigo um certo número de experiências, de conceitos e de crenças que não podem ser descartados. Ao contrário, devem ser considerados para que, a partir desses pontos, seja construído um ambiente sólido, aberto e plural, no qual também aprendam a assumir suas responsabilidades.

Como resposta para esse questionamento obtivemos o seguinte:

O comprometimento com a nossa profissão é um exercício pautado no conhecimento desenvolvido de forma crítica, então é muito importante que sejamos também profissionais em formação comprometidos com a curiosidade, com o interesse em aprender, em discutir, em problematizar. Nós alunos precisamos respeitar tanto os professores quanto os nossos colegas, participando das discussões, lendo os textos, opinando sobre a qualidade das aulas e desenvolvendo a nossa autonomia, achamos que esse é o caminho (Dupla 6).

Evidenciamos, dessa forma, que eles compreendem que essa ação de aprendizagem é dupla, requerendo um comprometimento de ambas as partes. Segundo Bulgraen (2010), refletir sobre a ação pedagógica consiste em considerar a prática social, de modo que tanto o educador quanto o educando tenham a capacidade de construir conhecimentos, de se expressar e de se (re)conhecerem enquanto agentes ativos e capazes de mudar. Além disso, os possíveis problemas enfrentados nas relações interpessoais e sua dinâmica fazem parte desse processo.

É fundamental que o ambiente de aprendizagem seja respeitoso e viabilizador de um saber dividido, que permita a criticidade. De acordo com Bulgraen (2010), talvez esse seja de fato o papel de quem aprende, tendo como responsabilidade o ensinar e o aprender conhecimentos construídos e elaborados pela humanidade durante a história, contribuindo para a formação de uma sociedade reflexiva, crítica e capaz de provocar transformações.

A formação de profissionais da educação para atuar nessa área tem sido pauta de discussões que trazem consigo desde a problematização no que se refere às diretrizes básicas dessa profissão até o sentido, social e institucionalmente, atribuído a ele. Desse modo, existem críticas sobre a fragmentação da formação do pedagogo que questionam essa divisão entre a teoria e a prática e essa distância entre a profissão de pedagogo e o trabalho docente (Libâneo \& Pimenta, 1999).

Defendemos a ideia de que tanto a ação como a teoria devem caminhar juntas e de que uma sem a outra resulta na limitação da atuação do professor. Esse distanciamento que ocorre na prática do educador acaba descaracterizando o profissional pedagogo, reduzindo sua atuação ao ensino das disciplinas e retirando-lhe as oportunidades de aliar a pesquisa à prática docente e pedagógica (Libâneo \& Pimenta, 1999). Esse pensamento também está implicado nas várias metodologias que exigem adesão do educador no intuito de trazer novas perspectivas para os alunos e fazer com que os mesmos aprendam de forma ativa. Entretanto, essas metodologias acabam tendo o objetivo inverso, sobrecarregando o professor e obrigando-o a realizar dinâmicas sem sentido educacional para atender a uma exigência institucional, além de haver a possibilidade de que ocorra uma confusão entre a didática e essas metodologias “ativas” ou limitando-a a elas (Libâneo \& Pimenta, 1999).

Faria (2018) questiona como se dá a relação entre pesquisa, didática e práxis na atual conjuntura acadêmica à luz das ideias de Karl Marx e de seu método dialético, de modo que se discuta sobre a importância de se pensar esses três conceitos como sendo algo dinâmico e interdependente, uma vez que um precisa do outro para se validar e se afirmar como saber.

No decorrer de seu texto, Faria (2018) faz uma crítica ao processo de formação dos professores e à didática, problematizando a necessidade de aprofundar os estudos sobre o lugar do sujeito na pesquisa, visto que o mesmo é uma importante categoria, sob o risco, em caso contrário, de se disseminar uma ideia de teoria distante da prática.

Nessa perspectiva, por meio da teoria do ser social em Karl Marx, esse sujeito torna-se fruto de práticas sociais e multiplamente determinado. Dessa forma, o lugar da práxis é utilizado como critério de verdade e o sujeito é resultante dessas relações sociais que são estabelecidas, apontando um conhecimento objetivo, dinâmico e relacional (Faria, 2018). Nesse contexto, cabe aos estudos pedagógicos apreender a prática social como ponto de início e de finalidade e a mediação seria a 
materialização nas relações de reciprocidade e interação entre os sujeitos. Aos pressupostos pedagógicos e didáticos caberia, de acordo com a autora, dar conta de explicar a ação educativa e o ensino como práticas complexas nas relações entre as pessoas, professores e alunos, transformando-se por meio de diversos contextos (Faria, 2018).

Finalmente, após a entrega das respostas, ainda durante as discussões que estávamos tendo sobre o ensino e as metodologias, lançamos a seguinte pergunta a todos: O que acharam de nosso momento envolvendo as fotografias?

Inicialmente, houve uma enxurrada de respostas, mas ao pedir-lhes para que falassem, um de cada vez, percebemos que estavam muito empolgados em partilhar as vivências desse momento uns com os outros. Todos, à sua própria maneira, destacaram os aspectos reflexivos dessa atividade, pontuando que, apesar de ter sido avaliativa e, aparentemente, simples, o processo de realização tornou-se complexo, visto que à medida em que iam lendo e se apropriando dos assuntos, deveriam escolher uma imagem que tentasse, minimamente, expressar um tipo específico de mensagem.

Afirmaram que isso, ao invés de desestimulá-los, tornava-se mais interessante. E que, por isso, acreditaram ser mais relevante não apenas fazer uma exposição fotográfica, mas transformar esse momento em uma pequena feira cultural. Durante o tempo que lhes foi dado para desenvolverem essa atividade, quase todos os alunos nos solicitaram que fizéssemos não somente uma exposição, mas que pudessem ornamentar seus espaços de acordo com o tema escolhido, de modo que enriquecessem ainda mais a atividade que estavam realizando.

Salientaram também que seria importante que tivessem tido um pouco mais de tempo para a execução do trabalho, inclusive para fotografar, uma vez que praticamente todos apenas levaram fotografias retiradas da internet. Também houve sugestões como a de, em caso de uma segunda versão dessa atividade em semestres subsequentes, que fosse convidado um fotógrafo profissional e que fosse proposta uma roda de conversa e/ou uma oficina de fotografia. Achamos essas contribuições muito interessantes, mas o que mais nos chamou atenção foi a forma como os alunos pensaram a realização da atividade e se dedicaram para a execução da mesma, atuando dialogicamente.

Concordamos que ser educador é oferecer a possibilidade de momentos reflexivos como o descrito anteriormente, reconhecendo que não é nossa função transmitir determinados conhecimentos aos alunos, mas fomentar espaços de diálogo, de reflexão, adaptando-os às necessidades do coletivo. Toda a atividade foi permeada pela partilha de experiências, facilitando a construção de significados para o que estava sendo realizado, indicando que houve um envolvimento da turma na atividade por meio do exercício da autonomia, da criticidade e do respeito.

\section{Considerações Finais}

Compartilhamos aqui uma atividade pedagógica que envolveu o uso de fotografias como forma de refletir sobre a dimensão da dialogicidade enquanto prática educativa na formação de alunos de um curso de Psicologia, de modo que pudemos perceber sua importância na perspectiva da práxis e do olhar dos próprios alunos que problematizaram a dialogicidade como elemento epistemológico, político e pedagógico em seu próprio processo de aprendizagem, além das contribuições que esse tipo de atividade pode trazer para o desenvolvimento do senso crítico e humano.

Acreditamos que seja necessário desenvolver outros estudos acerca dessa temática, mas nesta investigação já nos foi possível perceber que os alunos que participaram dessa experiência foram plenamente capazes de apontar o que era mais significativo em seu processo de aprendizagem, por exemplo, que o ambiente acadêmico fosse dinâmico, que permitisse a expressão e o diálogo e que a relação que os professores viessem a estabelecer com os discentes fosse respeitosa e minimamente acolhedora. Ao falarem sobre as aulas que tinham na instituição, frequentemente referiram-se à forma como os docentes conduziam suas explicações, à postura que assumiam diante da turma e às relações que estabeleciam em relação à mesma. 
Outro achado deste estudo diz respeito à concepção de ensino e aprendizagem dos discentes que elencaram como elementos fundamentais a esse processo o interesse em participar de sua própria aprendizagem - autonomia - e o compromisso de ambas as partes para que esse processo fosse, de fato, construtivo.

Desenvolver a autonomia enquanto educador também é fundamental para que esse projeto de ensino dialógico se concretize e para que possamos ter condições de atuar diante de tantas adversidades que enfrentamos na profissão. Não bastasse a complexidade de trabalhar com alunos de distintos contextos e da própria complexidade inerente ao processo de ensino e aprendizagem que, por si só, já demanda diferentes abordagens pedagógicas.

No meio de tudo isso está nossa própria vida pessoal da qual não podemos nos separar quando entramos em sala e quando temos que lidar com frequentes ataques oriundos das mais distintas instâncias, seja em relação à precarização da educação, à imposição de metodologias ditas "ativas", à exigência de uma postura profissional alheia à diversidade e ao perfil da turma, em suas dificuldades e potencialidades, ao excesso de atribuições burocráticas e maçantes e que em nada se relacionam ao desenvolvimento do ensino e da aprendizagem, à indiferença dos administradores das instituições às necessidades do docente, à exigência de um sem fim de formação docente, condição alinhada ao contexto capitalista no qual estamos inseridos, dentre outros aspectos que minam o exercício da profissão docente.

Concluímos que essa experiência possibilitou novas aprendizagens não somente aos alunos. Percebemos também que houve uma adesão à nossa proposta, o que permitiu momentos de partilha, discussão e (re)avaliação do modo de ser e estar em uma instituição de Ensino Superior. O processo de ensino e aprendizagem construído a partir da dialogicidade na prática educativa não possui uma prescrição ou modelo que podemos encontrar em manuais, fazendo-nos compreender que é necessário se construir, coletivamente, um conhecimento válido sobre a práxis do professor, o que pode tornar possível a formação de profissionais que questionem e reflitam sobre o seu lugar de trabalho e de fala.

\section{Referências}

Almeida, E. C. dos S. (2012). Ensino superior: representação social sobre prática educativa. Colóquio Internacional: Educação e Contemporaneidade, 6, São Cristóvão. (1-11).

Almeida, H. M. de. (2015). A didática no ensino superior: práticas e desafios. Estação Científica, Juiz de Fora, 14. (1-8).

Alves, R. Esquecer para saber. (2011). Folha de São Paulo: Cotidiano, São Paulo.

Anastasiou, L. das G. C. \& Alves, L. P. (Orgs). (2005). Processos de ensinagem na Universidade. Pressupostos para as estratégias de trabalho em aula. Joinville, SC: Univelle.

Barroso, B. O. (2015). A constituição do sujeito de aprendizagem: uma experiência da aprendizagem situada no Centro de Cultura e Desenvolvimento do Paranoá - CEDEP/DF. Tese (Doutorado Acadêmico em Educação) - Programa de Pós-Graduação em Educação, Centro de Educação, Universidade de Brasília. (281 f).

Bulgraen, V. C. O papel do professor e sua mediação nos processos de elaboração do conhecimento. (2010, ago./dez.). Revista Conteúdo, Capivari, 1(4). (30$38)$.

Cerqueira, B. M. \& Kelly, K. N. (2006). Análise das representações sociais dos professores dos cursos de história e geografia da UEFS sobre prática educativa. Colóquio sobre formação de professores: Ressignificar a profissão docente, 2, Salvador, Bahia: PROFORME/PPGEDUC/UNEB.

Faria, L. R. A. de. (2018). As Orientações Educativas Contra-Hegemônicas em Face dos Questionamentos Pós-Modernos. E a Didática com isso? In Marin, A. J. \& Pimenta, S. G. (Orgs.). Didática: Teoria e Pesquisa. Ceará: UECE. (67-80).

Flick, U. (2009). Introdução à pesquisa qualitativaArtmed.

Freire, P. (2006). Pedagogia da autonomia: saberes necessários à prática educativa. Paz e Terra.

Fontana, R. A. C. (2000). Mediação pedagógica na sala de aula. Autores Associados.

Libâneo, J. C. \& Pimenta, S. G. (1999). Formação de profissionais da educação: visão crítica e perspectiva de mudança. Educação e Sociedade, 68. (239-277).

Libâneo, J. C. (1994a). O processo de ensino na escola. Cortez. (77-118).

Libâneo, J. C. (1994b). Os métodos de ensino. Cortez. (149-176). 
Research, Society and Development, v. 10, n. 2, e3781029177, 2021

(CC BY 4.0) | ISSN 2525-3409 | DOI: http://dx.doi.org/10.33448/rsd-v10i2.9177

Libâneo, J. C. (1994c). A avaliação escolar. Cortez. (195-220).

Malusá, S. \& Feltran, R. C. F. (2003). A prática da docência universitária. Factash.

Minayo, M. C. de S. (2001). Pesquisa Social: Teoria, método e criatividade. Vozes.

Ribeiro, M. L. \& Soares, S. R. (2006). Análise das representações de prática educativa de docentes universitários formadores de professores: relatório de pesquisa. Feira de Santana: UEFS.

Rios, G. M.; Ghelli, K. G. M. \& Silveira, L. M. (2016). Qualidades de um professor universitário: perfil e concepções de prática educativa. Ensino Em Revista, Uberlândia, 23 (1). (135-154).

Saviani, D. (2008). A pedagogia no Brasil: história e teoria. Autores Associados.

Severino, A. J. (2007). Teoria e Prática Cientifica. Metodologia do trabalho cientifico. Cortez.

Zabala, A. (1998). A prática educativa: como ensinar. ArtMed.

Zabalza, M. A. (2004). Os professores universitários: seu cenário e seus protagonistas. Artmed. 